\title{
Detection Prediction and Mapping of Chromium through QGIS and Adsorption of Hexavalent Chromium by Modified Bio-Adsorbents: Kinetic and Adsorption study
}

Shivam Mani Tripathi ( $\nabla$ shivam.mani007@gmail.com )

Madan Mohan Malaviya University of Technology https://orcid.org/0000-0002-1400-4366

ShriRam Chaurasia

Madan Mohan Malaviya University of Technology

Pramod Kumar Sharma

IIT Roorkee: Indian Institute of Technology Roorkee

\section{Research Article}

Keywords: QGIS Mapping, Hexavalent Chromium, Kinetic study, Langmuir isotherm, Freundlich isotherm, Temkin isotherm.

Posted Date: June 7th, 2021

DOl: https://doi.org/10.21203/rs.3.rs-393778/v1

License: (c) (i) This work is licensed under a Creative Commons Attribution 4.0 International License.

Read Full License

Version of Record: A version of this preprint was published at Innovative Infrastructure Solutions on July 17th, 2021. See the published version at https://doi.org/10.1007/s41062-021-00563-4. 


\title{
Detection Prediction and Mapping of Chromium through QGIS and Adsorption of Hexavalent Chromium by Modified Bio-Adsorbents: Kinetic and Adsorption study
}

\begin{abstract}
:
Toxicity due to the presence of heavy metals in ground and surface water due to the release of effluents from industries holds the potency to cause temporary or permanent damage to the living organisms in the near vicinity of these industries. This paper aims to assess the vulnerability of groundwater resources owing to its contamination in Banthar Industrial Area. Using DRASTIC model in combination with Quantum Geographic Information System (QGIS), a groundwater vulnerability map was developed, which indicated that the dispersal of Chromium was in the range of $300-1000 \mu \mathrm{g} / \mathrm{l}$. In order to study the impact of Chromium dispersion, the authors proposed a batch adsorption testing of the Hexavalent Chromium $(\mathrm{Cr}$ (VI)) using different bio-adsorbent materials, keeping a $\mathrm{pH}$ range of 3-9 and the contact time between 080 minutes. Adsorption isotherms and Kinetic studies were also considered. All adsorbents followed the Langmuir isotherm $\left(\mathrm{R}^{2}>0.986\right)$, whereas Temkin isotherm stated the affinity of the adsorbents for the $\mathrm{Cr}$ (VI). The reactions between Chromium and the bio-adsorbents were found to follow pseudo-second order kinetics, which indicated that the reactions were exothermic. The results proposed that a modification in the bio-adsorbents caused an enhancement in the percent adsorption of $\mathrm{Cr}$ (VI) in comparison to the natural available bio-adsorbents.
\end{abstract}

Keywords: QGIS Mapping, Hexavalent Chromium, Kinetic study, Langmuir isotherm, Freundlich isotherm, Temkin isotherm.

\section{Introduction}

Easy, affordable and surplus availability of things develop a tendency in people to take it for granted. Such is the case with the natural resources provided to us by the environment. Water being three-fourths of earth's surface is not an exception. India being a developing country is already on its way to boost its manufacturing and other industrial processes in lieu of which little or no effort is seen at times to make the processes go in a circular fashion. One of the very serious problems is release of chemicals and waste in nearby streams and water bodies. Thus, heavy metals like Chromium, Lead and Arsenic etc. make their way to these water bodies from industries like cement industry, paints and pigment industry, paper mills, dyeing, tanneries etc.

Chromium is mainly existent in two forms, trivalent Chromium (Cr (III)) and hexavalent Chromium (Cr (VI)). $\mathrm{Cr}$ (III) is less toxic and insoluble in water, whereas $\mathrm{Cr}$ (VI) is highly toxic and soluble in water and exist as dense non-aqueous phase liquid (DNAPLs) being denser than the water [1]. Depending on the concentration and acidity, hexavalent Chromium can exist either as chromate $\left(\mathrm{CrO}_{4}^{2-}\right)$ or dichromate $\left(\mathrm{Cr}_{2} \mathrm{O}_{7}^{2-}\right)$. The commonly found Chromium species (all hexavalent Chromium) include $\mathrm{HCrO}_{4}^{-}, \mathrm{CrO}_{4}^{2-}$ and $\mathrm{Cr}_{2} \mathrm{O}_{7}^{2-}$ [2].

Chromium is one of the globally recognized carcinogenic metals and one of the eight most harmful chemicals to human beings [3]. Cr (VI) holds the potency to replace some proteins in blood of human body which can cause neuritis, nephritis, anemia, ulcer and other diseases. If $\mathrm{Cr}$ (VI) is present in blood for longer periods of time, certain respiratory problems and lungs cancer may be detected [4]. Cr (VI) is existent in 
groundwater where a cluster of industries is sited. It has also been found that on an average of 6-7 kilometers in their vicinity, Chromium traces are ought to be detected. Population living in these area regularly consume the toxic substances of the industries which acts as the starting point of serious health problems. Solid wastes from these industries may also contain the toxic compounds which leaches into groundwater and infiltrates to several kilometers through capillary action of the soil. Cr (VI) also affects the flora and fauna adversely. If water used for irrigation contains Chromium ions, then the plant parts have a tendency to absorb the Chromium ions in the descending order of roots, stems, leaves and fruits. According to IS 10500:2012, the permissible limit of Chromium is $0.05 \mathrm{mg} / \mathrm{l}$ [5]. Therefore, considering the protection of aquatic environment and the requirements on the discharge limits, it is of significant importance to reduce the $\mathrm{Cr}$ (VI) concentration from potential sources before they are discharged into water [6].

Use of various metals in various industrial processes, especially those having specific gravity of more than 5 , act as potential contaminant for both surface and sub-surface waters. In the region of Indo-Gangetic plain, near Unnao and nearby areas, there is a presence of tannery industries which constantly release Chromium into the nearby water bodies and contaminate them. An effort has been made to understand the levels of contamination of Chromium in the water bodies and to do a pattern study of how its plume spreads in nearby inhabited areas. Collection of different samples from different places in Banthar region of Unnao Industrial Area has been done and tested by ICP-MS. After the testing, a plotting of the groundwater contamination using DRASTIC model in combination with QGIS has also been done, which described the dispersal of Chromium in the region.

Nowadays, the treatment of $\mathrm{Cr}$ (VI) in industrial effluents includes ion exchange process, chemical precipitation, electrochemical generation, reverse osmosis, photo-catalytic oxidation etc. Generally, these processes are very complex in nature, have low efficiency, unsuitable for multiple pollutants and costly to perform. Among these technologies of remediation, adsorption technology is one of the efficient methods to treat the heavy metals from the water. Many low-cost bio adsorbents have been discovered which have good metal binding capacity. Bio-wastes which are locally available in bulk quantities such as wastes from agricultural activities, natural minerals and industrial byproducts can be used as bio-adsorbents for the metal ions. Few bio-adsorbents reported by the researchers are grape-bagasse, mango leaves, orange waste etc. Modified Orange Peel Powder (MOPP) in which orange peel powder is combined by ethylenediamine suggested a better efficiency of adsorption as compared to raw orange peel have also been reported [7]. It has been observed that a modification in the bio-adsorbents by the addition of a few compounds like sulphur, polyamines and esters can improve the efficiency of the adsorption [8].

In this paper, sawdust, rice husk, coir pith and vermiculite have been utilized. Vermiculite is a naturally occurring mineral; $1: 2$ type of alumino-silicate clay which contains aluminum-oxide $\left(\mathrm{Al}_{2} \mathrm{O}_{3}\right)$ and ferrous ion $\left(\mathrm{Fe}^{2+}\right)$ and helps to achieve better efficiency as a bio-adsorbent [ 2 and 9]. This work aims to prepare new adsorbents and analyze the effect of $\mathrm{pH}$ on the sorption and the effect of contact time of bio-adsorbents and $\mathrm{Cr}$ (VI). Besides these, kinetic and adsorption isotherms were also studied and different adsorption models were used to evaluate the experimental data in order to illustrate the possible adsorption mechanism.

\section{Materials and Methods}

\subsection{Characteristics of study area}

Unnao district of Uttar Pradesh, India lies between $26^{\circ} 05^{\prime}$ and $27^{\circ} 02^{\prime}$ north latitudes and $80^{\circ} 03^{\prime}$ and $81^{\circ} 03^{\prime}$ east longitudes. This location is situated in major physiographic units of Indo Gangetic Plain-Low land or younger alluvial plain, and upland or older alluvial plain. In this area, groundwater is available at very small depth as the pre and post monsoon depth of water level is in the range of 2.15 to $14.13 \mathrm{mbgl}$ and 0.60 to 
$13.33 \mathrm{mbgl}$. The major rivers Ganga and Sai are located near Unnao region which being perennial rivers, have plentiful amount of water. Availability of adequate quantity of water, land resources and easy connectivity to major cities attracted the Industrialists to setup factories at this location. Areas like Banthar, Jajmau in Unnao and nearby contains a cluster of tanneries, handlooms and textiles industries. These type of industries require enormous quantity of water and other chemicals for their processes and manufacturing of products. Effluents from such type of industries leads to increase in pollutants in their nearby locations as they discharge water without proper treatment, which contains a large amount of heavy metals like lead, Chromium and other chemicals which are hazardous. As reported in report of Central Ground Water Board report (2012), traces of Fluoride, Chromium and Arsenic were found beyond permissible limits in groundwater at some places of Unnao [10].

\subsection{Sampling Plan and Mapping of Chromium Dispersion}

A series of 25 India Mark II hand-pumps were selected from the near vicinity of Banthar Leather Technology Park. It covers an area of about $12 \mathrm{~km}^{2}$ and are assumed to be the potential sources of Chromium. The park is assumed to have contaminated the groundwater owing to the effluents of the industry, which are ill-treated or untreated. These effluents further percolate through surface and get mixed with the sub-surface water and disperse further in groundwater. Locations for sample collection were selected at different locations around the sources as shown in the Figure 1. Yellow portion includes the area covered by Unnao district and red portion depicts the sampling area from where the samples were collected. Sample area covers around 12 villages where the inhabited population was consuming this groundwater. On an average, from a depth of 125 feet, water samples of 1 litre and in $100 \mathrm{ml}$ of torsion bottles were collected separately. Torsion bottle used here was earlier washed by $\mathrm{HNO}_{3}-\mathrm{Ar}$ grade and double distilled water. Sample water for the testing of physical parameters was collected after operating the handpumps for 15 minutes. 1-litre bottle was filled up to the neck so that, there was no presence of air bubbles. $100 \mathrm{ml}$ torsion bottle was filled with syringe coupled with $0.22 \mu \mathrm{m}$ filter so that the organic matters get filtered. Later, in the laboratory, $2 \mu \mathrm{l}$ of suprapur $\mathrm{HNO}_{3}$ was added in $100 \mathrm{ml}$ of water sample and preserved for further metal testing.

Chromium was tested by Inductively Coupled Plasma Mass Spectrometry (ICP-MS) which has about 90\% accuracy. The ICP is involved in generation of a high temperature plasma source at $\sim 10,000^{\circ} \mathrm{C}$, through which the pre-treated sample is passed. The elements in the sample at such high temperature are ionized and directed further into the MS. Then MS sorts the ions according to their mass/charge ratio followed by directing them to an electron multiplier tube detector. This detector then identifies and quantifies each ion. Other physical parameters like $\mathrm{pH}$, TDS and conductivity were also measured. 


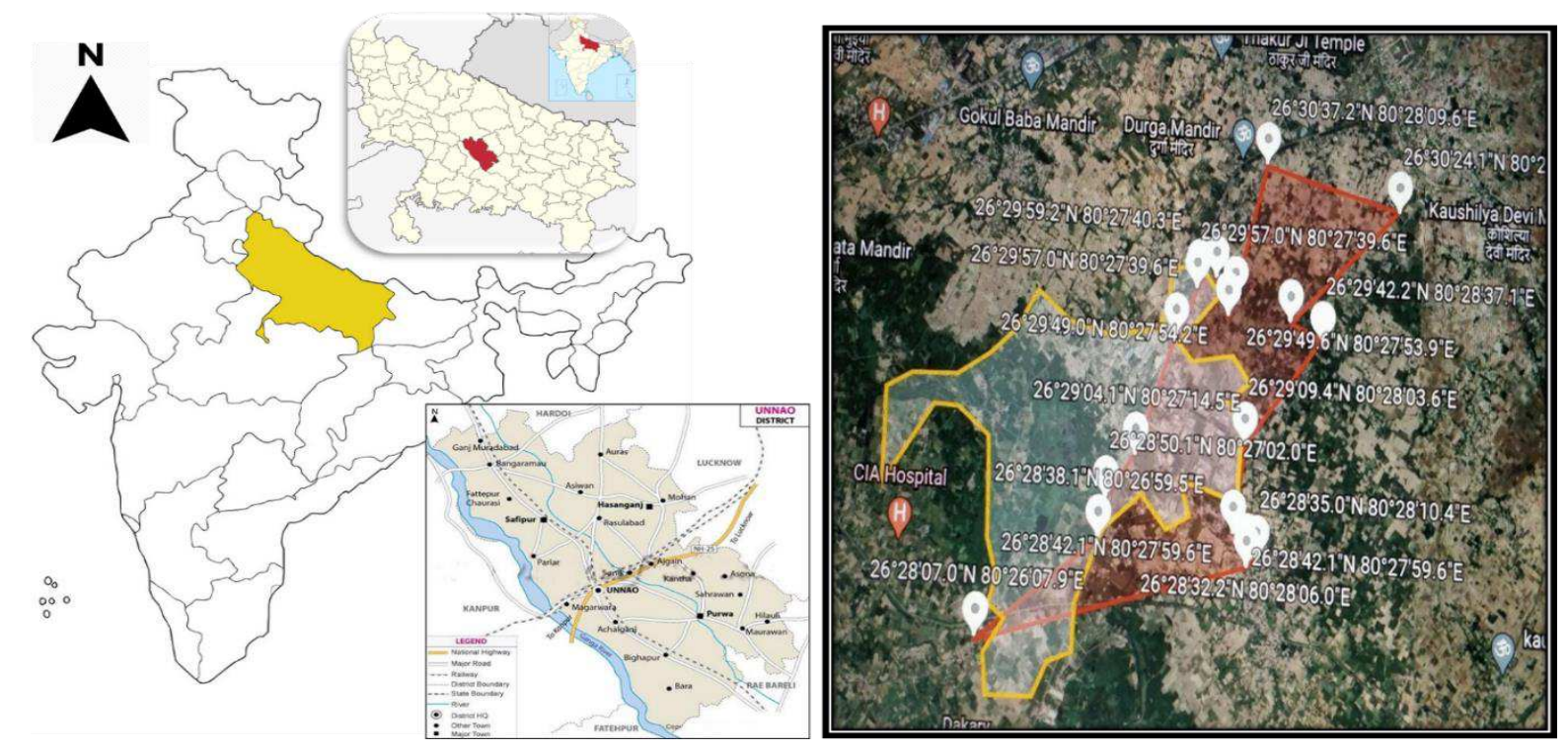

Figure 1: Selected sampling area Banthar region near Unnao, Uttar Pradesh India

In 1987, the United States Environmental Protection Agency (USEPA) funded research to develop a method for evaluating the pollution potential anywhere in the United States, which led to the successful development of the DRASTIC model [11]. The DRASTIC model was used to evaluate the relative vulnerability of areas towards groundwater contamination by focusing on the hydrogeological factors that influence pollution potential. The hydrogeological factors include depth to water, net recharge, aquifer media, soil media, topography, impact of the vadose zone and hydraulic conductivity which also happens to make up the acronym DRASTIC. The rating schemes and weights assigned to the seven hydrogeological factors that comprised the basis of the DRASTIC method were also adopted [11]. DRASTIC model has been used in detailed studies to delineate areas where aquifer vulnerability is higher and land use suggests a potential source of pollution [12]. It is an economical tool to identify the zones of concern and as a tool to overcome the problems of haphazard, uncontrolled development of land and of undesirable activities having an impact on groundwater quality [13]. As the coordinates of the sample locations were known, Chromium concentration and all other required variable data helped to create the mapping of the Chromium dispersion. In order to assess the distance and direction of the dispersion of the parameters and other geomorphology of the location which affected the dispersion of the Chromium DRASTIC model was combined with QGIS. As the Chromium was present beyond the permissible limit, it was required to reduce the concentration and bring its level below the permissible limit.

\subsection{Materials and preparation of Cationic Adsorbent}

$\mathrm{Cr}$ (VI) was prepared by using $\mathrm{K}_{2} \mathrm{Cr}_{2} \mathrm{O}_{7}$ and double-distilled water (for dilution) in order to achieve the desired concentration. Sawdust was collected from Timber Mill of Lucknow, India; Rice husk was collected from Jitendra Rice mill Faizabad Road, Lucknow India; Coir pith was collected from Bhola Garden Solution Lucknow, India and Vermiculite was sought from the Sakshi Fertilizer Pvt. Ltd. Lucknow, India. All other reagents were bought from New Science Emporium, Gorakhpur, India. All these chemicals were of analytical grade and were used as received.

Raw sawdust, rice husk, coir pith and vermiculite were washed several times with double distilled water to remove the impurities and other particulate matter. It was further dried at $80^{\circ} \mathrm{C}$ in a convection oven for 24 hours. The dried raw sawdust was sieved in the range of 45 to $150 \mu \mathrm{m}$ and further activated by $\mathrm{H}_{2} \mathrm{SO}_{4}$. 50 
gram of Sawdust was activated by refluxing it with $300 \mathrm{ml}$ of 40 weight $\% \mathrm{H}_{2} \mathrm{SO}_{4}$ for 5 hours in a flask. The suspension was cooled and washed with double distilled water and $1 \%$ sodium bicarbonate was added to remove the residual acid. Again sawdust was dried in oven at $80^{\circ} \mathrm{C}$ for 24 hours [14] and then stored in desiccator for further use.

Raw dried rice husk (20 grams) was soaked with sodium hydroxide solution ( $250 \mathrm{ml}$ and $2.5 \mathrm{~mol} / \mathrm{l})$. The suspension was agitated for 3 hours and rice husk was removed. The treated rice husk was washed with distilled water until $\mathrm{pH}$ turned to neutral. The activated rice husk was further oven dried at $60^{\circ} \mathrm{C}$ for 24 hours [15] and kept in desiccator for further use.

20 grams of dried raw coir pith was added with 1 litre of acrylic acid and 500ml of $\mathrm{HNO}_{3}$ in 2 litres of flask then $25 \mathrm{ml}$ of ceric ammonium nitrate is added. Nitrogen bubble was introduced into the suspension for 4 hours. Then the coir pith was washed with hot water until its $\mathrm{pH}$ reached to its equilibrium. Then coir pith was oven dried for 24 hours at $60^{\circ} \mathrm{C}$ and stored in desiccator [16].

Cleaned vermiculite was soaked into $40 \mathrm{ml}$ solution of $\mathrm{Mg}\left(\mathrm{NO}_{3}\right)_{2} \cdot 6 \mathrm{H}_{2} \mathrm{O}, \mathrm{Al}\left(\mathrm{NO}_{3}\right)_{2} \cdot 9 \mathrm{H}_{2} \mathrm{O}$, Urea and then stirred for 30 minutes alongwith with heating the solution in oven at $120^{\circ} \mathrm{C}$ for 24 hours. After cooling it to room temperature, the sample was filtered and washed with deionized water and dried in oven for 8 hours at $60^{\circ} \mathrm{C}$ [17] and further stored in desiccator for further use.

\subsection{Batch Experiment}

Fixed amount of activated sawdust, rice husk, coir pith and vermiculite was added to $250 \mathrm{ml}$ sealed conical flask containing $100 \mathrm{ml} \mathrm{Cr}$ (VI) solution having different initial concentration. Flasks were put into the shaking thermostat machine at a speed of $200 \mathrm{rpm}$. Aqueous sample of $10 \mathrm{ml}$ was withdrawn at equilibrium and filtered by using $0.25 \mu \mathrm{m}$ size filter. The capacity of $\mathrm{Cr}$ (VI) adsorption by different adsorbing media was calculated under different conditions to understand the changes in adsorption process. The equilibrium adsorption concentration $\mathrm{q}_{\mathrm{e}}\left(\mathrm{mgg}^{-1}\right)$ was determined by equation:

$$
\mathrm{q}_{\mathrm{e}}=\frac{\mathrm{V}\left(\mathrm{C}_{\mathrm{o}}-\mathrm{C}_{\mathrm{e}}\right)}{\mathrm{W}}
$$

The efficiency of adsorption (percentage of removal efficiency) was determined by equation:

$$
\text { Adsorption (\% of removal efficeny) }=\frac{\left(C_{o}-C_{e}\right)}{C_{o}} \times 100
$$

where, $\mathrm{C}_{\mathrm{o}}$ and $\mathrm{C}_{\mathrm{e}}$ are the initial and equilibrium concentration of $\mathrm{Cr}(\mathrm{VI})$ in $\mathrm{mg} / \mathrm{l}$ respectively, $\mathrm{V}$ is the volume of the solution in litre and $\mathrm{W}$ is the weight of the adsorbent in gram and $\mathrm{q}_{\mathrm{e}}$ is the adsorption percentage in $\mathrm{mgg}^{-1}$.

\subsection{Mechanism of $\mathrm{Cr}$ (VI) absorption}

The surface molecule of bio-adsorbents has $-\mathrm{C}=\mathrm{O},-\mathrm{CHO},-\mathrm{COOH},-\mathrm{CN},-\mathrm{OH},-\mathrm{CONH}_{2},-\mathrm{NH}_{2},-\mathrm{NH}$, $-\mathrm{N},-\mathrm{C}-\mathrm{O}-\mathrm{C}$ functional groups. The probable mechanism for $\mathrm{Cr}(\mathrm{VI})$ atoms is to bind with the hetero atoms having donor pair of electrons in the functional groups present on the bio-adsorbent's surface (as shown in the Figure 2). The electron donor present in the functional groups forms a weak coordinate bond. The linking of hydrogen atom between two electronegative oxygen atoms attached to the $\mathrm{Cr}$ (VI) molecule and the bio-adsorbent molecule leads to the formation of hydrogen bonds on the surface. Similar findings of the attachment of Chromium moiety to the functional groups present on the bio-adsorbents have also been reported $[18,19]$. 
The smaller size of Chromium ion and its enhanced reactivity to attain a stable structural configuration facilitated it to adhere onto the surface of biomass containing free functional groups which resulted in bioadsorption. This mechanism of adsorbent-adsorbate helps in the removal of the metals effectively from $\mathrm{Cr}$ (VI) polluted water.

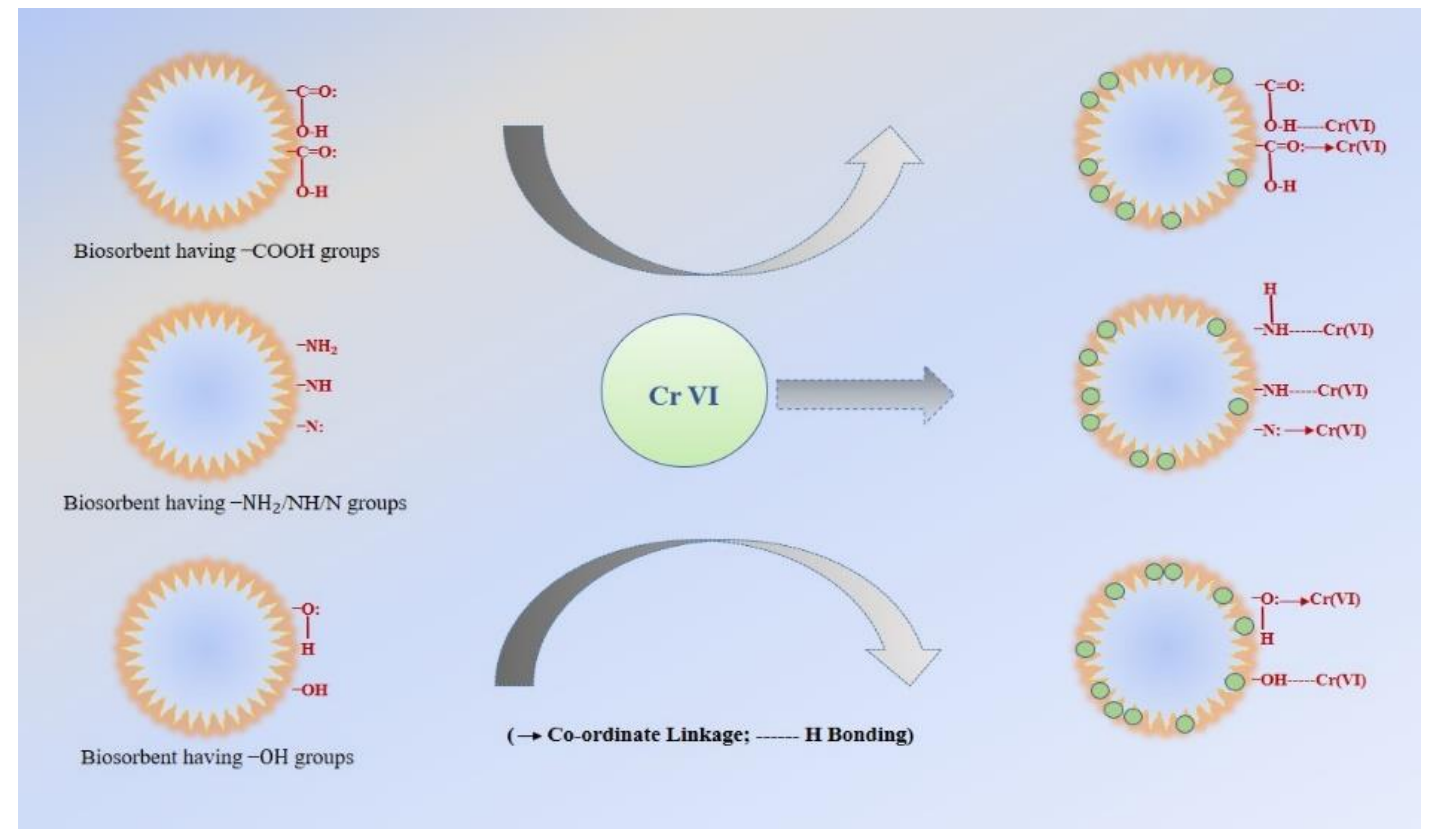

Figure 2: Probable mechanism of $\mathrm{Cr}(\mathrm{VI})$ absorption

\section{Results and discussion}

\subsection{Detection Prediction and Mapping of Chromium}

It was found that the hand-pumps near the tanneries had maximum electrical conductivity i.e. $2089.6 \mu \mathrm{S} / \mathrm{cm}$ which indicated that the groundwater is highly contaminated as the permissible limit of electrical conductivity lies between 200 and $800 \mu \mathrm{S} / \mathrm{cm}$. Total Dissolved Solids (TDS) was also found to be maximum in near vicinity to the source which is beyond the permissible limit $(400-2000 \mathrm{mg} / \mathrm{l})$; acceptable limit of TDS is $500 \mathrm{mg} / \mathrm{l}$. pH of the groundwater water varied from 6 to 7.3. The presence of Chromium was tested from the samples of different locations using ICP-MS and was found to be in the range of 1000-3000 $\mu \mathrm{g} / \mathrm{l}$. The distance between these two points is $6.48 \mathrm{~km}$ as shown in Table1. It was also found that the Chromium variation was not linear at some places. A sudden surge in the levels of Chromium was also observed due to the presence of other mixing sources in the region as well as the geological features.

Dispersion of Chromium was observed with the help of QGIS mapping. The investigated area consisted of various soil types namely clay, silt, sand, gravel, and kankar sediments of quaternary age as this area is the central Ganga alluvial plain. Digital Elevation Model (DEM) of the investigated area was developed using QGIS. Using the Spatial Analyst function of GIS, the slope of the ground surface from the grid of the DEM was computed. Through the use of Raster Extraction function of QGIS, the contour was determined based on the DEM raster at $30 \mathrm{~m}$ resolution. It was assumed that the unsaturated zone is a continuation and extension of the aquifer media and thus the same GIS shape file. The groundwater map with dispersal of Chromium in the investigated area (as shown in Figure 3) showed moderate to highly vulnerable areas prone to contamination. This pattern is mainly dictated by the shallow water level and the variation in soil media, aquifer media, vadose zone and topography. 
Table 1: Presence of Chromium in the Investigated Area with Physical Parameters

\begin{tabular}{|c|c|c|c|c|c|c|c|c|c|c|}
\hline \multirow{2}{*}{$\begin{array}{l}\text { S. } \\
\text { No. }\end{array}$} & \multirow{2}{*}{ Location of Sites in Unnao region } & \multirow{2}{*}{ Latitude } & \multirow{2}{*}{ Longitude } & \multirow{2}{*}{$\begin{array}{l}\text { Distance } \\
(\mathbf{k m})\end{array}$} & \multirow{2}{*}{ pH } & \multirow{2}{*}{$\begin{array}{c}\text { TDS } \\
\text { (in ppm) }\end{array}$} & \multirow{2}{*}{$\begin{array}{c}\text { Hydraulic } \\
\text { Conductivity } \\
(\mu \mathrm{S} / \mathrm{cm})\end{array}$} & \multicolumn{3}{|c|}{ Chromium $(\mathrm{Cr})$ in ppm } \\
\hline & & & & & & & & Total & (VI) & (III) \\
\hline 1 & Banthar Industrial Area-I & 26.486 & 80.468 & 3.74 & 7.0 & 590 & 465.7 & 0.089 & 0.021 & 0.068 \\
\hline 2 & Banthar Industrial Area-II & 26.478 & 80.467 & 3.30 & 6.4 & 1160 & 922.4 & 0.168 & 0.043 & 0.122 \\
\hline 3 & Banthar Industrial Area-III & 26.478 & 80.466 & 3.28 & 6.5 & 1010 & 828.4 & 0.120 & 0.020 & 0.100 \\
\hline 4 & Banthar Industrial Area-IV & 26.476 & 80.468 & 3.37 & 6.5 & 1550 & 1283.6 & 0.208 & 0.135 & 0.073 \\
\hline 5 & Banthar Industrial Area-V & 26.476 & 80.470 & 3.51 & 6.3 & 1350 & 1164.2 & 0.180 & 0.098 & 0.082 \\
\hline 6 & Banthar; near Durga Temple & 26.476 & 80.468 & 3.40 & 6.2 & 1630 & 1425.4 & 0.220 & 0.109 & 0.111 \\
\hline 7 & Village Poni; Bramha & 26.469 & 80.436 & 0.00 & 6 & 2000 & 2089.6 & 1.000 & 0.676 & 0.323 \\
\hline 8 & Village Gahara; Sikandarpur karn & 26.477 & 80.450 & 1.72 & 6.8 & 950 & 761.2 & 0.115 & 0.054 & 0.061 \\
\hline 9 & Village Gahara; Sikandarpur & 26.481 & 80.451 & 2.01 & 6.8 & 740 & 547.8 & 0.145 & 0.036 & 0.109 \\
\hline 10 & $\begin{array}{l}\text { Village Gahara; Near Hanuman } \\
\text { Temple }\end{array}$ & 26.484 & 80.454 & 2.56 & 7.4 & 580 & 425.4 & 0.078 & ND & 0.078 \\
\hline 11 & Shekhpur Village & 26.499 & 80.461 & 3.94 & 7.3 & 410 & 300.0 & 0.045 & ND & 0.045 \\
\hline 12 & Shekhpur Nari & 26.500 & 80.461 & 4.15 & 6.3 & 1020 & 771.6 & 0.129 & 0.064 & 0.065 \\
\hline 13 & Nari Market & 26.500 & 80.461 & 4.18 & 6.5 & 840 & 656.7 & 0.108 & 0.043 & 0.065 \\
\hline 14 & Gram Panchayat; Nari-I & 26.500 & 80.463 & 4.36 & 6.5 & 560 & 417.9 & 0.076 & 0.004 & 0.07 \\
\hline 15 & Gram Panchayat; Nari-II & 26.499 & 80.466 & 4.38 & 6.7 & 470 & 350.7 & 0.055 & ND & 0.055 \\
\hline 16 & Gram Panchayat; Shekhpur-I & 26.510 & 80.469 & 5.71 & 6.5 & 770 & 579.1 & 0.095 & ND & 0.095 \\
\hline 17 & Gram Panchayat; Shekhpur-II & 26.497 & 80.465 & 4.21 & 6.4 & 830 & 625.4 & 0.105 & 0.05 & 0.098 \\
\hline 18 & Gram Panchayat; Shekhpur-III & 26.497 & 80.465 & 4.18 & 6.5 & 480 & 350.7 & 0.057 & ND & 0.057 \\
\hline 19 & Shekhpur & 26.495 & 80.459 & 3.61 & 6.3 & 1460 & 1131.3 & 0.480 & 0.23 & 0.25 \\
\hline 20 & Shekhpur; near Shiv Temple & 26.499 & 80.461 & 4.12 & 7.2 & 980 & 723.9 & 0.125 & 0.044 & 0.081 \\
\hline 21 & Himachal Kheda & 26.497 & 80.473 & 4.57 & 7.4 & 520 & 373.1 & 0.074 & ND & 0.074 \\
\hline 22 & Himachal Kheda & 26.497 & 80.473 & 4.77 & 7.3 & 490 & 346.3 & 0.049 & ND & 0.049 \\
\hline 23 & Himachal Kheda & 26.497 & 80.474 & 4.88 & 7.2 & 520 & 353.7 & 0.063 & ND & 0.063 \\
\hline 24 & Babu Kheda & 26.495 & 80.477 & 4.97 & 7.4 & 440 & 314.9 & 0.047 & ND & 0.047 \\
\hline 25 & $\begin{array}{l}\text { Amir Ali Kheda; Bhagwati Prasad; } \\
\text { Vikas khand }\end{array}$ & 26.507 & 80.486 & 6.48 & 7.1 & 400 & 283.6 & 0.030 & ND & 0.030 \\
\hline
\end{tabular}

*ND $=$ Not Detectable 


\section{Sampling Area Near Banthar Industrial Area}

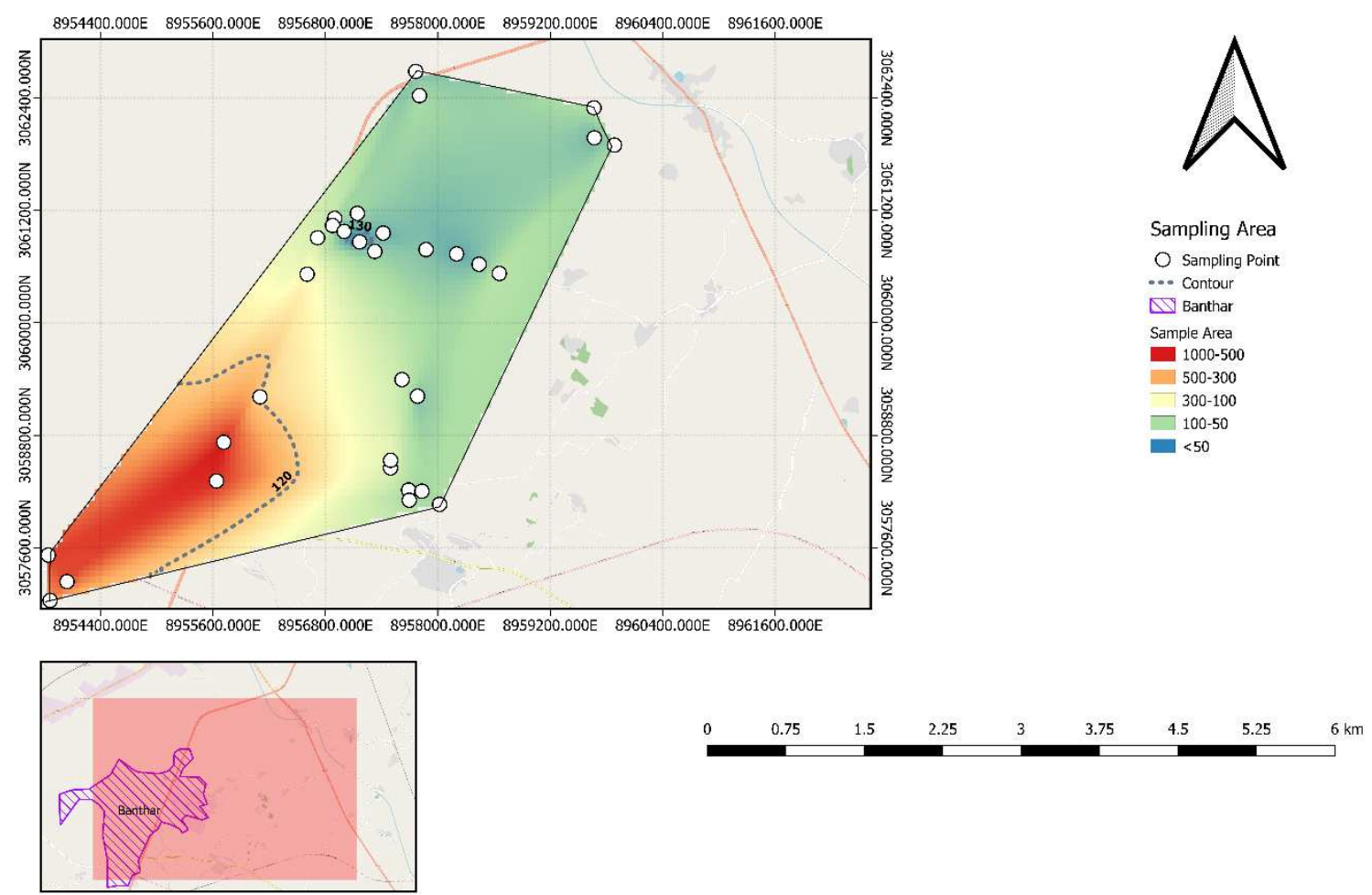

Figure 3: Mapping of investigated area through QGIS showing dispersion of Chromium

\subsection{SEM Analysis}

To understand the surface morphology and composition of ions on the bed of adsorbents, Scanning Electron Microscopy (SEM) and EDX analysis has been conducted. Analysis has been done by electron microscope equipped with X-ray analyzer. This study helps to understand the arrangements of the particles in adsorbent samples. Back scattered electron and secondary electron analyze the surface morphology of conducting and non-conducting materials. X-ray analyzer (EDX) finds the compositions of different ions present on the bed of the adsorbent.

Raw sawdust was characterized as a highly oriented structure; materials were highly fibrous which showed the anisotropic character of the sawdust. This isotropy changed when sawdust was treated with sulphuric acid. It produced modifications in the fibers and created void channels, thereby preserving a honeycomb structure as shown in Figure 4 (a) \& 4 (b). Modified sawdust was more porous as compared to the raw sawdust. The chemical composition of the raw sawdust and modified sawdust also amended as raw sawdust contained C- $45.54 \%, \mathrm{Zn}-1.79 \%$, O- $30.62 \%, \mathrm{Ca}-0.64 \%, \mathrm{Cu}-2.39 \%$ and $\mathrm{Au}-19.04 \%$ whereas modified sawdust contained C- $47.02 \%, \mathrm{Zn}-1.21 \%$, O- $36.78 \%$, Ca- $0.45 \%, \mathrm{Cu}-1.89 \% \mathrm{Au}-12.15 \%$ and $\mathrm{S}-0.5 \%$ by weight. Sulphur ion was introduced in the modified sawdust because the sawdust was treated by sulphuric acid. It also increased the percentage of oxygen by weight which helped to activate the sawdust for Cr (VI).

Rice husk was modified by $\mathrm{NaOH}$, which had a crystalline structure compared to raw rice husk as shown in Figure 4 (c) \& 4 (d). Surface composition of raw rice husk included C, O and Si whereas modified rice husk did not contain $\mathrm{Si}$ component. The elimination of silica ions from rice husk resulted in a better surface morphology in terms of surface becoming more porous, crystalline and efficient as compared to raw rice 
husk. This modification in surface morphology characteristics of the activated rice husk made it an adsorbent of $\mathrm{Cr}(\mathrm{VI})$.

The surface morphology of the modified coir pith was rougher as compared to the raw coir pith, as shown in Figure 4 (e) \& 4 (f). In the modified coir pith, acrylic acid $\left(\mathrm{C}_{2} \mathrm{H}_{3} \mathrm{COOH}\right)$ was chemically bonded to the surface of the coir pith. Previously Deng and Ting (2005) reported that surface morphology was uneven and rougher after the graft co-polymerization of acrylic acid on raw biomass as compared to raw biomass [20]. The surface composition of raw coir pith was composed of $\mathrm{C}$ and $\mathrm{O}$ of $53.89 \%$ and $31.84 \%$ respectively whereas the modified coir pith had increased percentage of $\mathrm{C}$ and $\mathrm{O}$ i.e. $62.121 \%$ and $39.81 \%$ respectively. $\mathrm{C}$ and $\mathrm{O}$ got increased due to reaction of acrylic acid with the coir pith which activated the coir pith and provided a better efficiency than the raw coir pith.

From SEM, it was analyzed that the raw vermiculite has typical flat, smooth and multi-layered structure whereas the modified structure of vermiculite (transformed by $\mathrm{Mg} \mathrm{Al-LDH}$ ), a large number of hexagonal layers were present on the interlayer surface and the external side of vermiculite surface was covered by half hexagon of Mg Al-LDH as shown in Figure 4 (g) \& 4 (h). Surface composition by X-ray analysis (EDX analysis), showed the presence of $\mathrm{Mg}, \mathrm{Al}$ and $\mathrm{O}$ with an $\mathrm{Mg} / \mathrm{Al}$ molar ratio of about 2 . Therefore, it resulted that $\mathrm{Mg} \mathrm{Al-LDH}$ can be adjusted by means of concentration of metal salts in reaction solution.
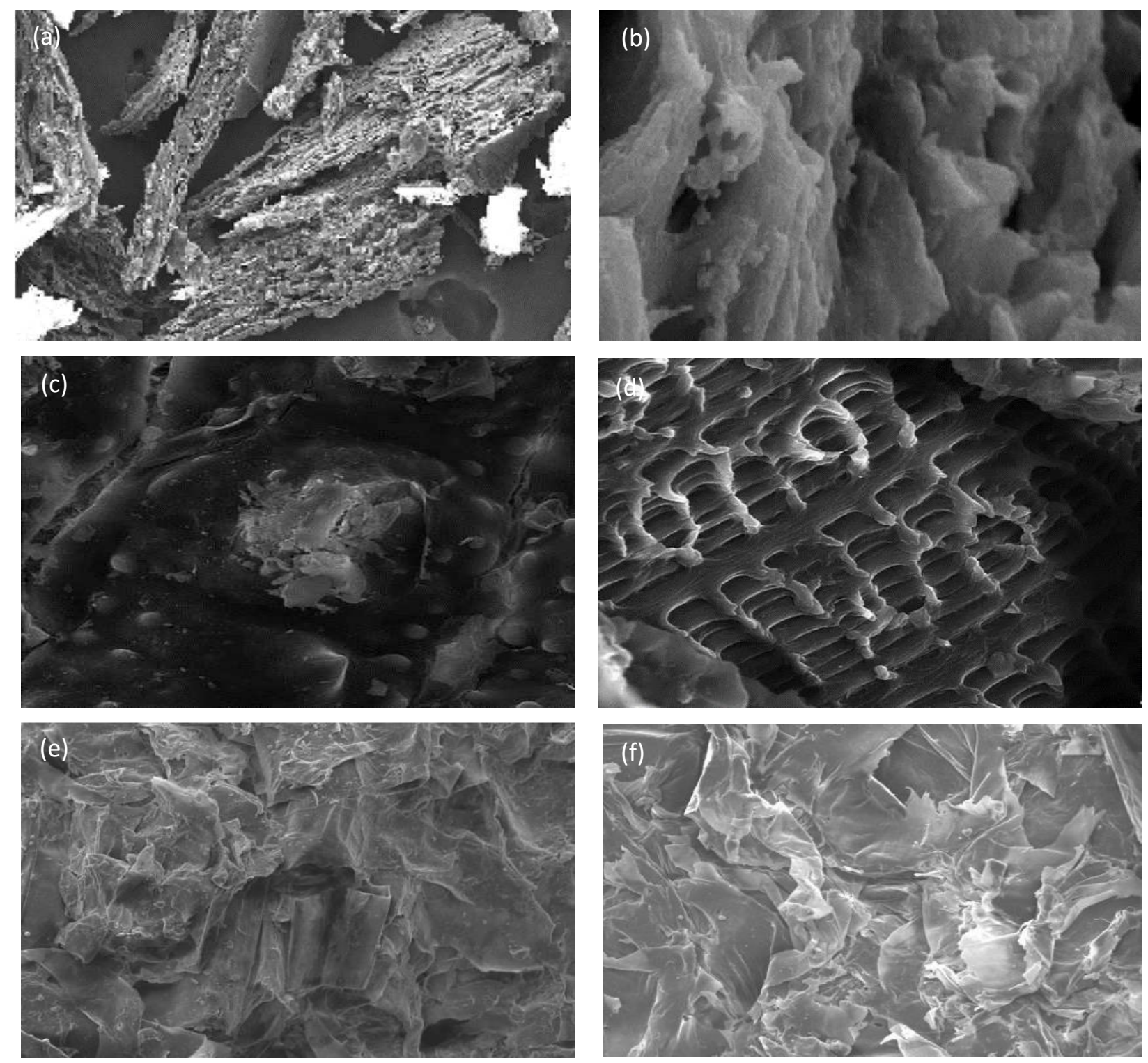

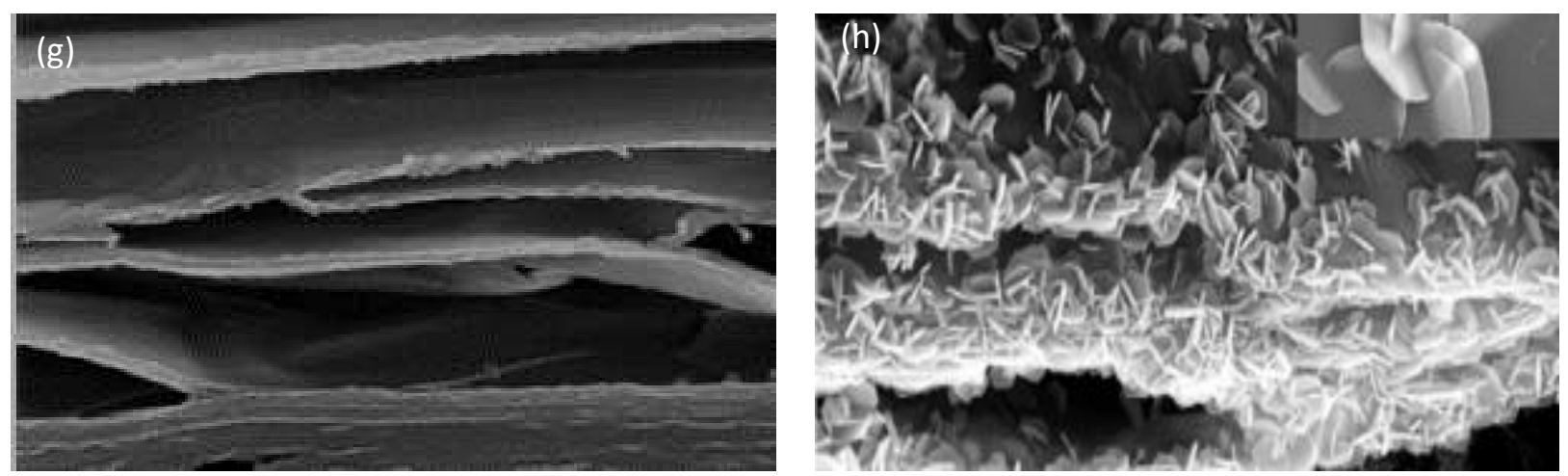

Figure 4: SEM image of (a) Raw Sawdust (b) Activated Sawdust (c) Raw Rice husk (d) Activated Rice husk (e) Raw Coir pith (f) Activated Coir pith (g) Raw Vermiculite (h) Activated Vermiculite

\subsection{Effect of Contact time on Chromium adsorption by different adsorbent}

Contact time is one of the most vital factors in the batch adsorption analysis. In this stage, the contact time of different adsorbents vary and all other parameters like temperature, adsorbent dose, initial concentration of Chromium and $\mathrm{pH}$ remain constant. An optimum temperature of $25^{\circ} \mathrm{C}$, an adsorbent dose of $1.5 \mathrm{~g} / \mathrm{l}, \mathrm{pH}$ equal to 3, initial concentration of $\mathrm{Cr}$ (VI) as $100 \mathrm{mg} / \mathrm{l}$ and agitation time equal to $300 \mathrm{rpm}$ were kept constant and contact time of the different adsorbents was varied in the range of 5-80 minutes. The effect of contact time on adsorption efficiency of $\mathrm{Cr}(\mathrm{VI})$ has been shown in Figure 5. Adsorption rate increased rapidly and the optimal removal of $\mathrm{Cr}$ (VI) using adsorbents coir pith and sawdust within 40 minutes reached $83.5 \%$ and $88.4 \%$ respectively. Vermiculite within 20 minutes reached an adsorption limit of $47.5 \%$. Rice husk does not reach its equilibrium, as it was observed in contact time period of 5 minutes to 1 hour, adsorption was nearly constant, but after 60 minutes it was observed that its efficiency rapidly changed from $20.1 \%$ to $34.06 \%$.

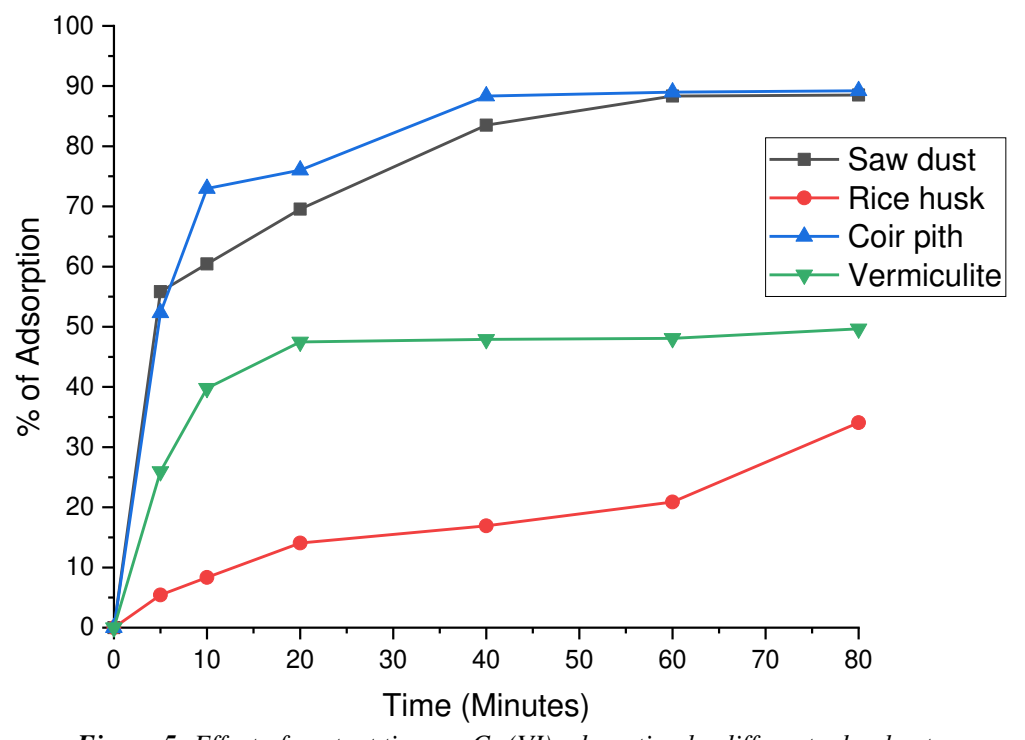

Figure 5: Effect of contact time on Cr (VI) adsorption by different adsorbent

\subsection{Effect of pH on Chromium adsorption by different adsorbent}

Aqueous-regime $\mathrm{pH}$ plays a very important role to adsorb the metal ion onto solid-liquid interface [21] $\mathrm{pH}$ also controls the degree of ionization and speciation of the adsorbate. Experiments were carried under an optimized condition of temperature $=25^{\circ} \mathrm{C}$, agitation speed $=300 \mathrm{rpm}$, contact time $=60$ minutes, adsorbent dose $=1.5 \mathrm{~g} / \mathrm{l}$ and initial Chromium concentration $=100 \mathrm{mg} / \mathrm{l} . \mathrm{pH}$ of the solution was adjusted with 
$\mathrm{H}_{2} \mathrm{SO}_{4}$ and $\mathrm{NaOH}$. Effect of $\mathrm{pH}$ on adsorption of $\mathrm{Cr}(\mathrm{VI})$ by different adsorbent are shown in Figure 6 . An observation in a $\mathrm{pH}$ range of 3 to 9 proved that at lower $\mathrm{pH}$, adsorption was higher. In case of sawdust and coir pith, effective adsorption in a $\mathrm{pH}$ range of 3 to 6 was observed. Comparable pattern was also perceived in the case of rice husk and vermiculite as formerly reported in study [22]. This might be due to the weakening of electrostatic force of attraction between the oppositely charged adsorbate and adsorbent which finally leads to the reduction of the sorption efficiency [23]. Adsorption of $\mathrm{Cr}$ (VI) varies as a function of $\mathrm{pH} \mathrm{H}_{2} \mathrm{CrO}_{4}, \mathrm{HCrO}_{4}^{-}, \mathrm{Cr}_{2} \mathrm{O}_{7}^{-}$and $\mathrm{CrO}_{4}^{2-}$ ions appear as dominant species [24]. At $\mathrm{pH} 3, \mathrm{HCrO}_{4}^{-}$ is the dominant species. The surface of adsorbent is positive at low $\mathrm{pH}$ and this may lead to the binding of negatively charged $\mathrm{HCrO}_{4}^{-}$ions. The species of $\mathrm{HCrO}_{4}^{-}$is the most effortlessly exchanged with $\mathrm{OH}^{-}$ions at the active surface of adsorbent, under acidic conditions as shown in following reactions [25].

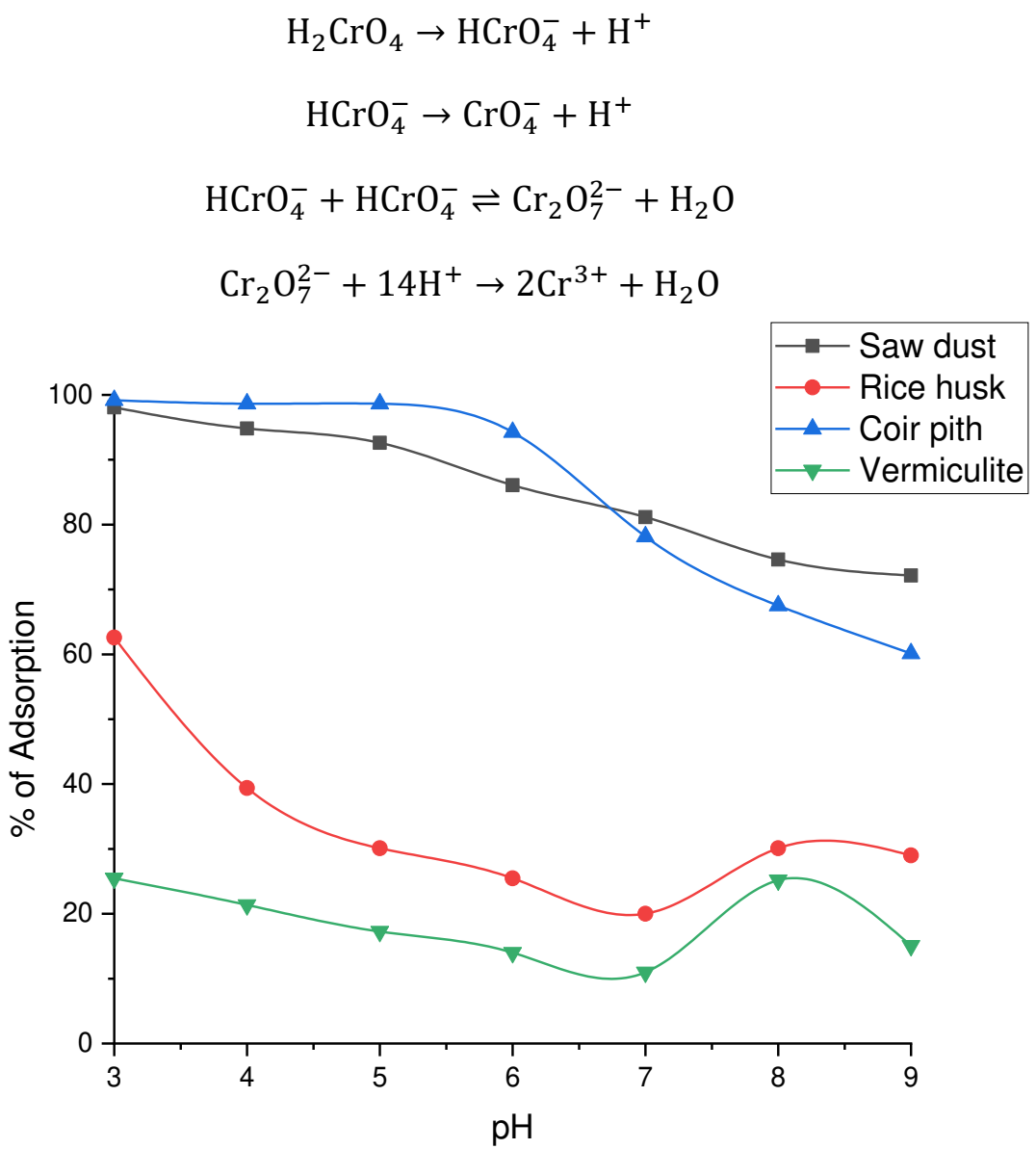

Figure 6: Effect of pH on Cr (VI) adsorption by different adsorbent

\subsection{Effect of different Adsorbent Doses on Chromium adsorption}

At this stage, it was examined that the effect of $\mathrm{Cr}$ (VI) adsorption by variation of doses of different adsorbents by considering all other conditions constant at optimum level ( $\mathrm{pH}$ of aqueous-regime 3, agitation speed $300 \mathrm{rpm}$, contact time 60 minutes and temperature $25^{\circ} \mathrm{C}$ ). The adsorbent doses of different materials i.e. activated sawdust, rice husk, coir pith and vermiculite was varied from 0.25 to $2.00 \mathrm{~g} / \mathrm{l}$ in the solution, where $\mathrm{Cr}$ (VI) was $100 \mathrm{mg} / \mathrm{l}$. It was observed that the sawdust and coir pith showed similar variations, when the adsorbent dose was $0.25 \mathrm{~g} / \mathrm{l}$. Their adsorption percentage was calculated by equation 2 and the results obtained were $48.67 \%$ and $44.70 \%$ respectively. As further increment was done in the dose of sawdust from 
0.50 to $1.00 \mathrm{~g} / \mathrm{l}$, a sudden increase in adsorption of $\mathrm{Cr}(\mathrm{VI})$ was observed. As the adsorbent dose of sawdust and coir pith was kept at $1.50 \mathrm{~g} / \mathrm{l}$, the obtained adsorption percentage was $78.34 \%$ and $76.9 \%$ respectively, which on increment remains nearly constant (as shown in Figure 7). In the case of rice husk, when adsorbent dose was kept at $0.25 \mathrm{~g} / \mathrm{l}$, the obtained adsorption percentage was $25.89 \%$. As the dose of adsorbent was increased to $1.5 \mathrm{~g} / \mathrm{l}$, the adsorption percentage reached its optimum level. In the case of vermiculite, effects of doses on adsorption was nearly constant after $0.75 \mathrm{~g} / \mathrm{l}$ however it was earlier reported in study by [26] that as the adsorbent dose was increased, adsorption percentage of metal ion also enhanced.

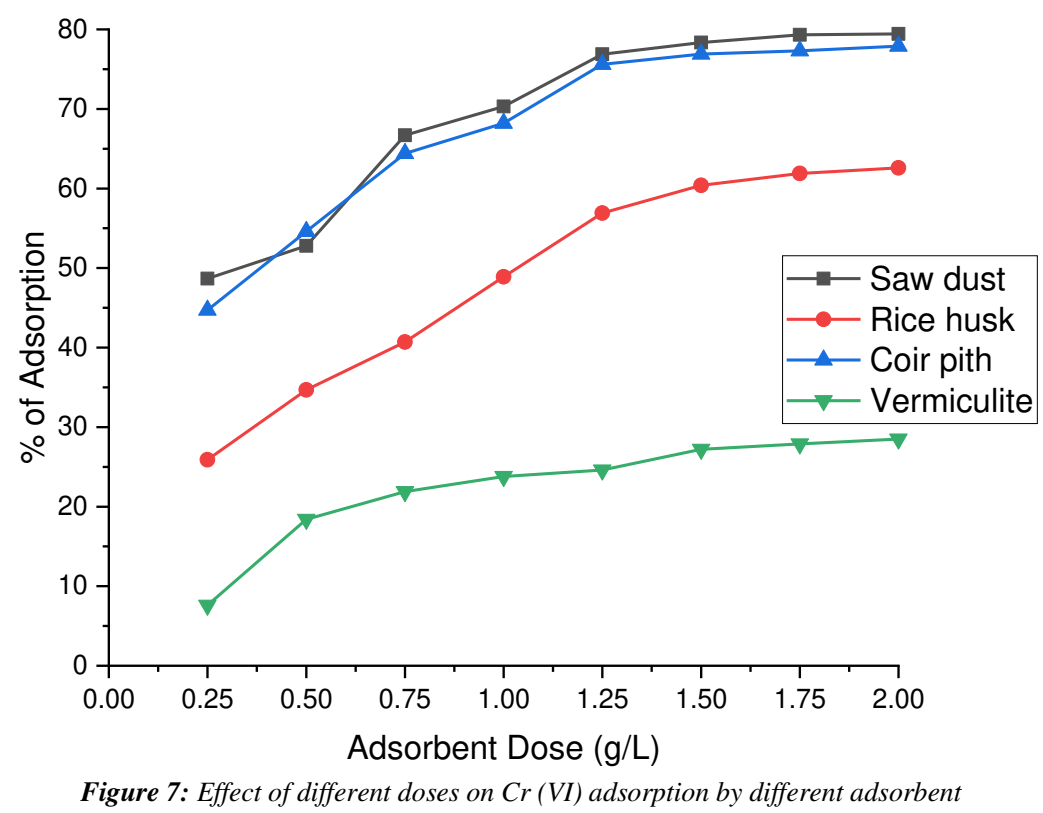

\subsection{Adsorption isotherm}

Adsorption isotherm describes the interaction of adsorbate with adsorbent. The experimental adsorption data of Cr (VI) ion with different adsorbents such as sawdust, rice husk, coir pith and vermiculite was analyzed using Langmuir, Freundlich and Temkin models. The initial concentration of $\mathrm{Cr}$ (VI) affected the adsorption percentage of the test bio sorbents. An increasing trend in the adsorption percentage of sawdust and coir pith can be seen from Figure 8. Rice husk was also found to follow the same pattern as that of saw dust and coir pith but had lower adsorption percentage because the surface morphology of rice husk is less porous and had lower affinity with $\mathrm{Cr}(\mathrm{VI})$. In the case of vermiculite, the adsorption percentage was more than the sawdust. After a further increase in the initial concentration of $\mathrm{Cr}(\mathrm{VI})$, the adsorption percentage got decreased and finally was found to be less than that of rice husk. At this stage, it was observed that the adsorption percentage was found to be in the order as: Coir pith > Sawdust > Rice husk > Vermiculite.

Langmuir adsorption model is based on the assumption that the maximum adsorption corresponds to a saturated monolayer of solute molecules on the adsorbent surface with no lateral interaction between the adsorbed molecules [27]. The Freundlich model can be applied to multilayer adsorption with non-uniform distribution of adsorption and the affinities over the heterogeneous surface [28]. The Temkin isotherm model assumes that the adsorption of all molecules decreases linearly with the increase in coverage of the adsorbent surface, and that the adsorption is characterized by a uniform distribution of binding energies, up to a maximum binding energy [29]. 


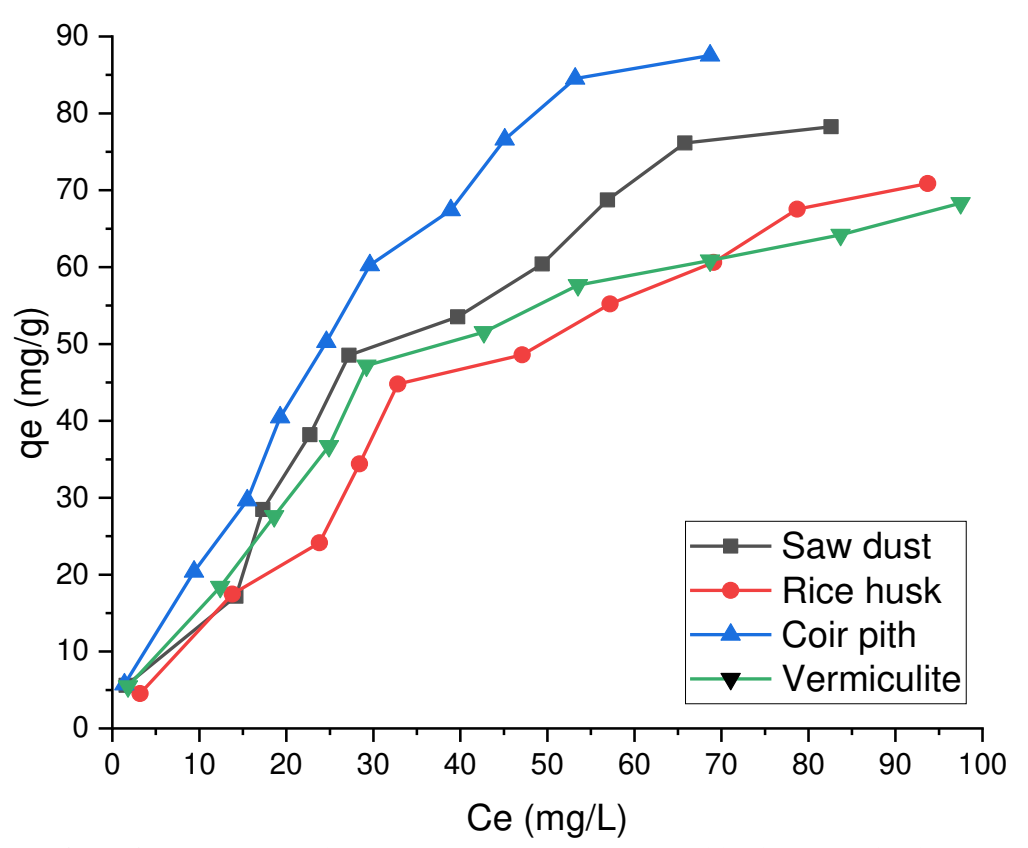

Figure 8: Effect of initial concentration on $\mathrm{Cr}(\mathrm{VI})$ removal by different adsorbents

Adsorption isotherm (Langmuir, Freundlich and Temkin models) were applied to know the equilibrium adsorption characteristics. Equation 7 represents the Langmuir isotherm.

$$
\mathrm{q}_{\mathrm{e}}=\frac{\mathrm{q}_{\max } \mathrm{K}_{\mathrm{L}} \mathrm{C}_{\mathrm{e}}}{1+\mathrm{K}_{\mathrm{L}} \mathrm{C}_{\mathrm{e}}}
$$

The Langmuir isotherm was transformed into its linear form as represented in equation 8 to determine the adsorption parameter.

$$
\frac{1}{q_{e}}=\frac{1}{K_{L} q_{\max }} \cdot \frac{1}{C_{e}}+\frac{1}{q_{\max }}
$$

where, $\mathrm{q}_{\max }$ is the maximum adsorption percentage $(\mathrm{mg} / \mathrm{g})$ and $K_{L}(\mathrm{mg} / \mathrm{g})$ is Langmuir isotherm constant which shows that the binding affinity between $\mathrm{Cr}(\mathrm{VI})$ and adsorbent bead.

Separation factor $\left(R_{L}\right)$ is calculated by equation

$$
\mathrm{R}_{\mathrm{L}}=\frac{1}{1+\mathrm{C}_{\mathrm{o}} \times \mathrm{K}_{\mathrm{L}}}
$$

where, $R_{L}$ is the dimensionless Langmuir constant which indicates the adsorption nature to be either unfavorable, if $R_{L}>1$, linear if $R_{L}=1$, favourable if $0<R_{L}$.

Freundlich's isotherm is represented by equation 10:

$$
\mathrm{q}_{\mathrm{e}}=\mathrm{K}_{\mathrm{f}} \mathrm{C}_{\mathrm{e}}^{\frac{1}{n}}
$$

The linear form of Freundlich's isotherm is shown in equation 11.

$$
\log q_{e}=\log K_{f}+\frac{1}{n} \log C_{e}
$$

where, $K_{f}$ is Freudlich's constant and used to measure the adsorption percentage and $\frac{1}{n}$ is the adsorption intensity. The value of $\frac{1}{n}$ explain the adsorption process to be either favorable $\left(0.1<\frac{1}{n}<0.5\right)$ or unfavorable. 
Temkin's isotherm represents by equation 12

$$
\mathrm{q}_{\mathrm{e}}=\frac{\mathrm{RT}}{\mathrm{b}_{\mathrm{T}}} \ln \mathrm{A}_{\mathrm{T}}+\left(\frac{\mathrm{RT}}{\mathrm{b}_{\mathrm{T}}}\right) \ln \mathrm{C}_{\mathrm{e}}
$$

where, $b_{T}=$ slope of the graph between $\mathrm{q}_{\mathrm{e}} \ln \mathrm{C}_{\mathrm{e}}$

$$
\mathrm{A}_{\mathrm{T}}=\exp \left(\frac{\text { intercept }}{\mathrm{b}_{\mathrm{T}}}\right)
$$

$\mathrm{A}_{\mathrm{T}}$ is the equilibrium binding constant $\left(\mathrm{L} \mathrm{mol}^{-1}\right)$ corresponding to the maximum binding energy, $\mathrm{b}_{\mathrm{T}}$ is related to the adsorption heat, $\mathrm{R}$ is the universal gas constant $\left(8.314 \mathrm{~J} \mathrm{~K}^{-1} \mathrm{~mol}^{-1}\right)$ and $\mathrm{T}$ is the temperature $(\mathrm{K})$.

In this study, three theoretical models Langmuir, Freundlich and Temkin isotherms were used to examine the adsorption characteristics of different adsorbents for $\mathrm{Cr}$ (VI) uptake as shown in Figures 9, 10 and 11. The Langmuir's isotherm describes the monolayer adsorption of pollutant onto the adsorbent surface having finite number of adsorption sites whereas Freundlich's isotherm supports that adsorption occurs on heterogeneous surface of the adsorbent. [30].

The following results presented in Table 2 shows that the Langmuir isotherm model was the best fit because the values of linear regression coefficient $\left(R^{2}>0.986\right.$ for all cases) of this isotherm was observed to be higher than the Freundlich isotherm model $\left(\mathrm{R}^{2}>0.955\right.$ for all cases) which shows monolayer adsorption of $\mathrm{Cr}$ (VI) on different adsorbents. Maximum adsorption percentage $\left(\mathrm{q}_{\max }\right)$ for $\mathrm{Cr}$ (VI) observed that the Sawdust has maximum adsorption percentage followed by rice husk, coir pith and vermiculite. The values of separation factor $\left(\mathrm{R}_{\mathrm{L}}\right)$ for all adsorbents are less than one, which favoured the adsorption phenomenon. Temkin isotherm model explained that all adsorption took place as exothermic process as $b_{\mathrm{T}}$ value is found to be positive in all cases. $\mathrm{A}_{\mathrm{T}}$ describes the affinity of sorbents for $\mathrm{Cr}(\mathrm{VI})$ and $\mathrm{R}^{2}>0.62$ in all cases.

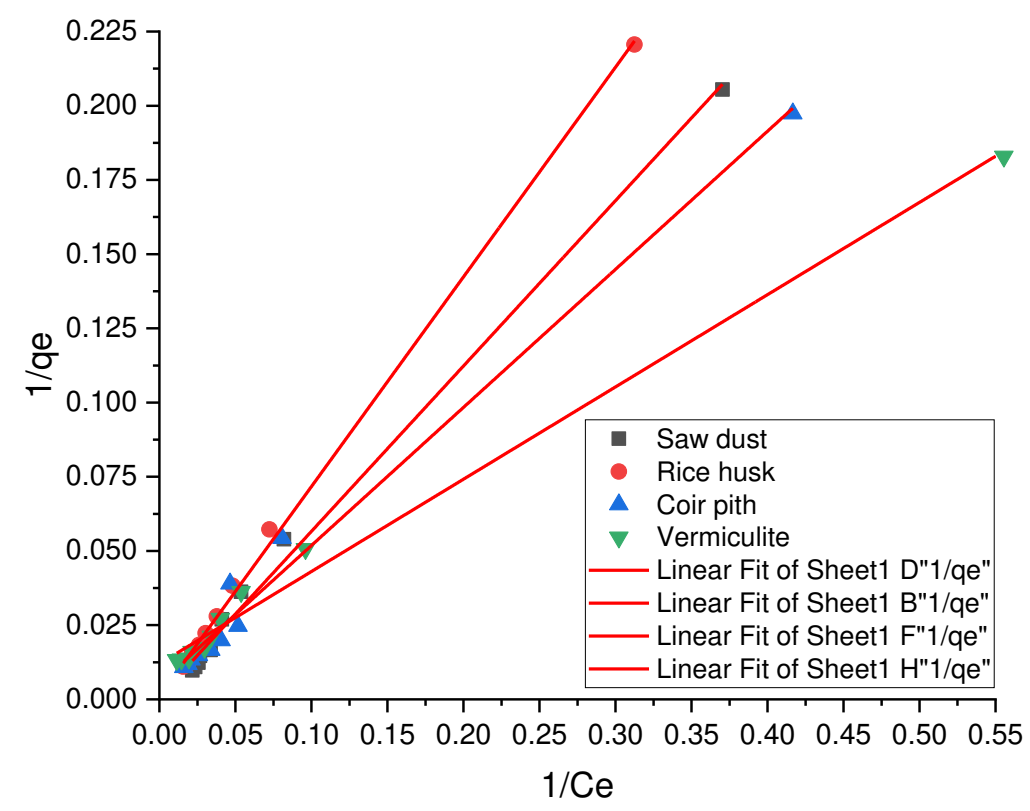

Figure 9: Langmuir's isotherm plots for the bio-sorption of $\mathrm{Cr}$ (VI) onto different adsorbents 


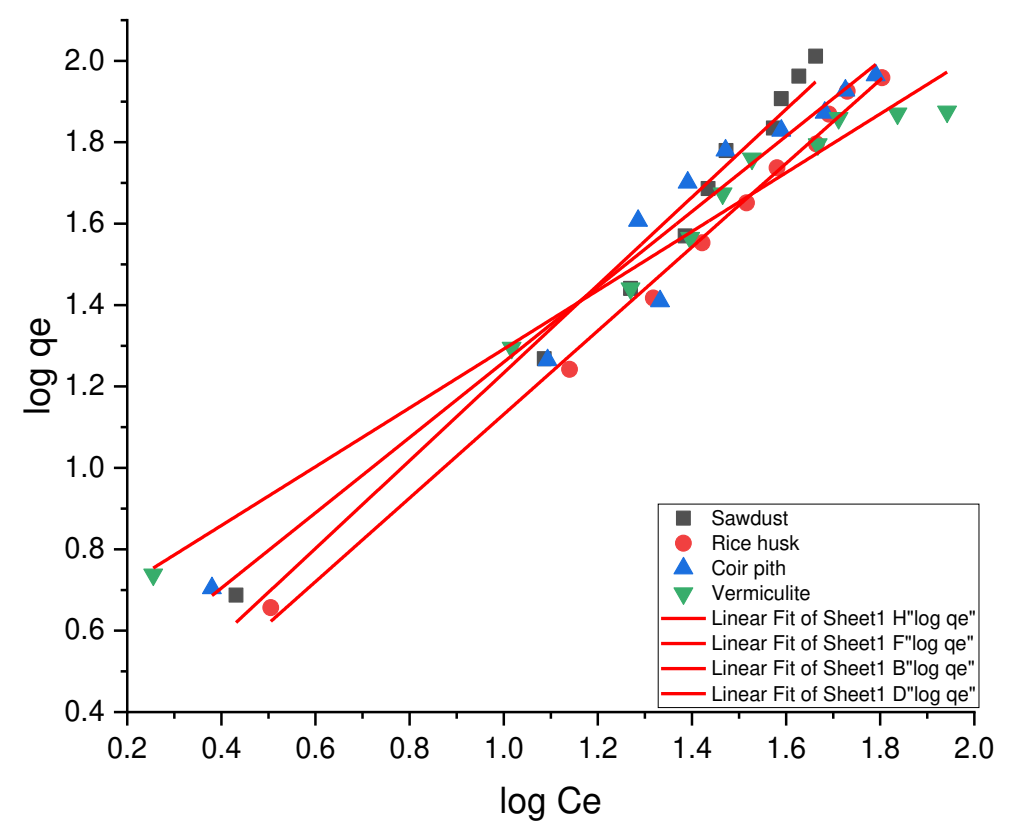

Figure 10: Freundlich's isotherm plots for the bio-sorption of $\mathrm{Cr}(\mathrm{VI})$ onto different adsorbents

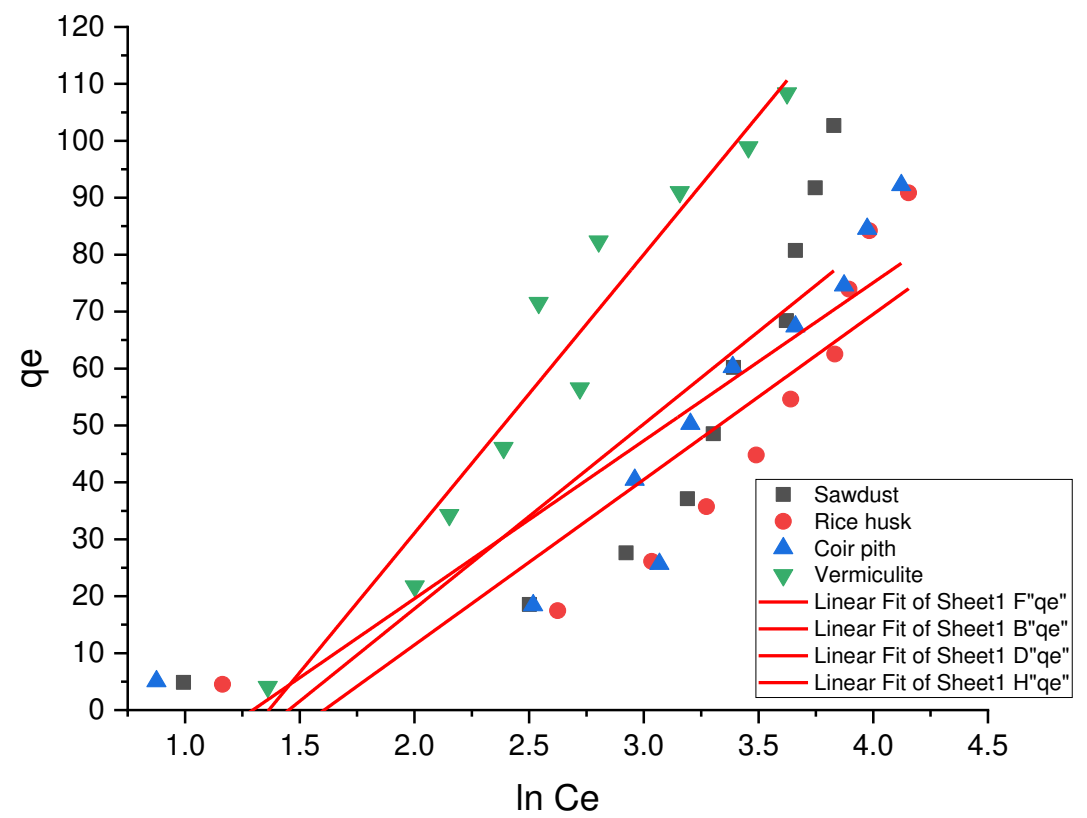

Figure 11: Temkin's isotherm plots for the bio-sorption of $\mathrm{Cr}(\mathrm{VI})$ onto different adsorbents

Table 2: Isotherm parameters for the removal of $\mathrm{Cr}(\mathrm{VI})$ by different adsorbents

\begin{tabular}{|l|l|l|l|l|l|}
\hline \multicolumn{1}{|l|}{ Type of isotherm } & Sawdust & Rice husk & Coir pith & Vermiculite \\
\hline \multirow{4}{*}{ Langmuir } & $\mathrm{q}_{\max }(\mathrm{mg} / \mathrm{g})$ & 112.72 & 95.23 & 63.32 & 43.27 \\
\cline { 2 - 6 } & $\mathrm{K}_{\mathrm{L}}(\mathrm{L} / \mathrm{mg})$ & 0.0016 & 0.0015 & 0.0011 & 0.0385 \\
\cline { 2 - 6 } & $\mathrm{R}_{\mathrm{L}}$ & 0.8626 & 0.8706 & 0.467 & 0.2061 \\
\cline { 2 - 6 } & $\mathrm{R}^{2}$ & 0.9951 & 0.9984 & 0.9861 & 0.9907 \\
\hline \multirow{3}{*}{ Freundlich } & $\mathrm{K}_{\mathrm{f}}$ & 1.4279 & 1.2702 & 2.1596 & 3.7102 \\
\cline { 2 - 6 } & $1 / \mathrm{n}$ & 1.1533 & 1.0275 & 0.9253 & 0.7224 \\
\cline { 2 - 6 } & $\mathrm{R}^{2}$ & 0.9759 & 0.9942 & 0.9554 & 0.9748 \\
\hline
\end{tabular}


Table 3: Temkin isotherm model for the removal of $C r(V I)$ by different adsorbents

\begin{tabular}{|c|c|c|c|c|}
\hline Temkin isotherm & Sawdust & Rice husk & Coir pith & Vermiculite \\
\hline $\mathrm{B}_{\mathrm{T}}(\mathrm{J} / \mathrm{mol})$ & 32.474 & 29.052 & 27.758 & 48.959 \\
\hline $\mathrm{K}_{\mathrm{T}}(\mathrm{L} / \mathrm{mg})$ & 0.2341 & 0.2006 & 0.2738 & 0.2553 \\
\hline $\mathrm{R}^{2}$ & 0.6917 & 0.7694 & 0.7906 & 0.9376 \\
\hline
\end{tabular}

\subsection{Kinetic isotherm}

Kinetic study has been carried out to find out the reaction time in order to achieve the equilibrium using the optimum amount of bio-adsorbents and maintaining the $\mathrm{pH}$ level simultaneously. The equilibrium adsorption study was conducted with $\mathrm{Cr}$ (VI) solution of concentration, $\mathrm{C}_{\mathrm{o}}=10-200 \mathrm{mg} / \mathrm{l}$ with different adsorbents in optimum doses of $1.5 \mathrm{~g} / \mathrm{l}$. Initial $\mathrm{pH}$ of the solution was set at 3 using $0.1 \mathrm{M} \mathrm{H}_{2} \mathrm{SO}_{4} / 0.1 \mathrm{M}$ $\mathrm{NaOH} .250 \mathrm{ml}$ of $\mathrm{Cr}$ (VI) sample was then shaken at $300 \mathrm{rpm}$ at $25^{\circ} \mathrm{C}$ for 60 minutes. After the maintenance of the state of equilibrium, different adsorbents were separated from the solution through $2 \mu \mathrm{m}$ filtration, the filtrate was then analyzed using spectrophotometer. Adsorption rate of $\mathrm{Cr}$ (VI) was analyzed by using pseudo $1^{\text {st }}$ order and pseudo $2^{\text {nd }}$ order kinetic models by different adsorbents. The pseudo $1^{\text {st }}$ order model is represented in equation 13 and pseudo $2^{\text {nd }}$ order model is represented by equation in 14 .

$$
\begin{gathered}
\ln \left(q_{e}-q_{t}\right)=\ln q_{e}-K_{1} t \\
\frac{t}{q_{e}}=\frac{1}{K_{2} q_{e}^{2}}+\frac{1}{q_{e}}
\end{gathered}
$$

where, $q_{t}$ represents the adsorption percentage $(\mathrm{mg} / \mathrm{g})$ at time $\mathrm{t}, K_{1}\left(\mathrm{~min}^{-1}\right)$ is the equilibrium rate constant $K_{2}\left(\mathrm{~g} \mathrm{mg}^{-1} \mathrm{~min}^{-1}\right)$ is the equilibrium rate constant.

The rapid-kinetic behavior indicated that the adsorption process was dependent on the available number of binding sites on the adsorbents for the uptake of $\mathrm{Cr}(\mathrm{VI})$. After equilibrium time, the adsorbent surface is achieved [31]. In the present study, the pseudo $1^{\text {st }}$ and $2^{\text {nd }}$ order rate mentioned in equation 13 and 14 respectively were employed for further evaluation of the kinetic parameters of $\mathrm{Cr}$ (VI) adsorption on different adsorbents.

The fitting of equilibrium data of two kinetic models with the $\mathrm{Cr}$ (VI) and different adsorbents are shown in figure 12 and 13 respectively, and the results of respective kinetic parameters in Table 4 . A pseudo $2^{\text {nd }}$ order kinetic model was observed to be the best fit in the explanation of the kinetics of Cr (VI) adsorption with different adsorbents because it exhibited higher values of linear regression coefficient $\left(\mathrm{R}^{2}>0.999\right.$ in all cases) in comparison to pseudo $1^{\text {st }}$ order model $\left(\mathrm{R}^{2}<0.799\right.$ in all cases). There exists a rational agreement between the experimental and calculated adsorption percentage $\left(q_{e}\right)$ values which favors the pseudo $2^{\text {nd }}$ order kinetic model. The results showed that the concentration of bio-sorbents and $\mathrm{Cr}(\mathrm{VI})$ were responsible for the rate determining step during the binding of $\mathrm{Cr}(\mathrm{VI})$ with the different adsorbents. This also suggests that the adsorption of $\mathrm{Cr}(\mathrm{VI})$ on beds takes place through chemisorption mechanism. This study has also been also verified previously [32]. 


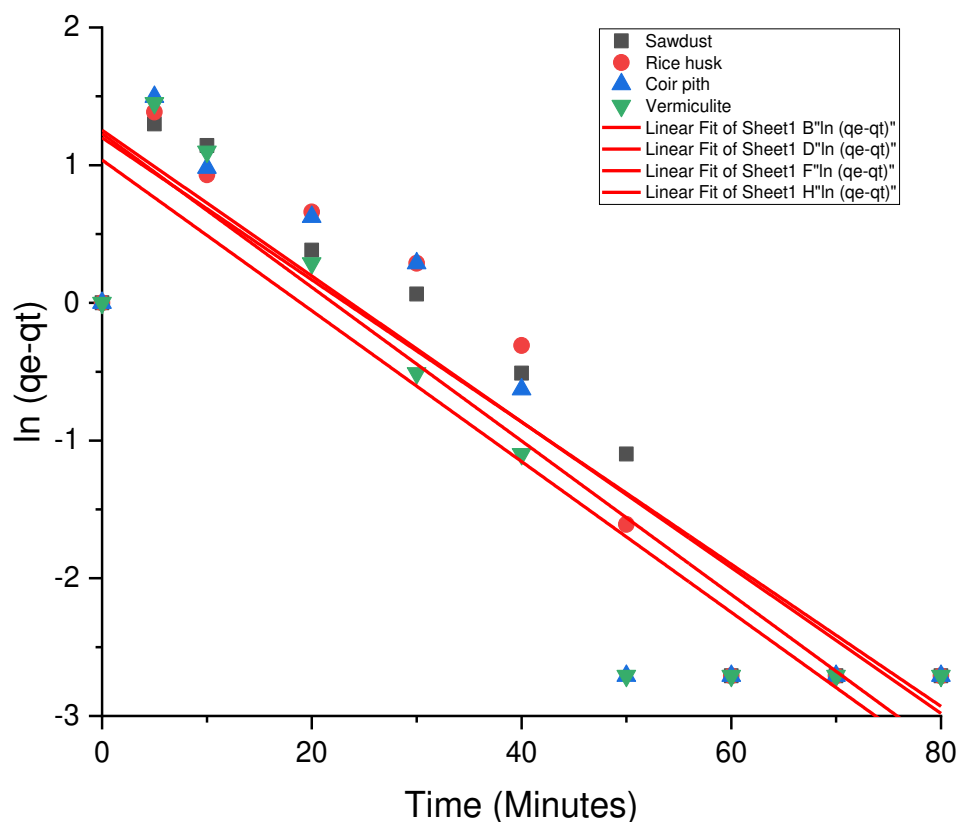

Figure 12: Pseudo-first-order kinetic plots for the bio-sorption of $\mathrm{Cr}$ (VI) onto different adsorbents

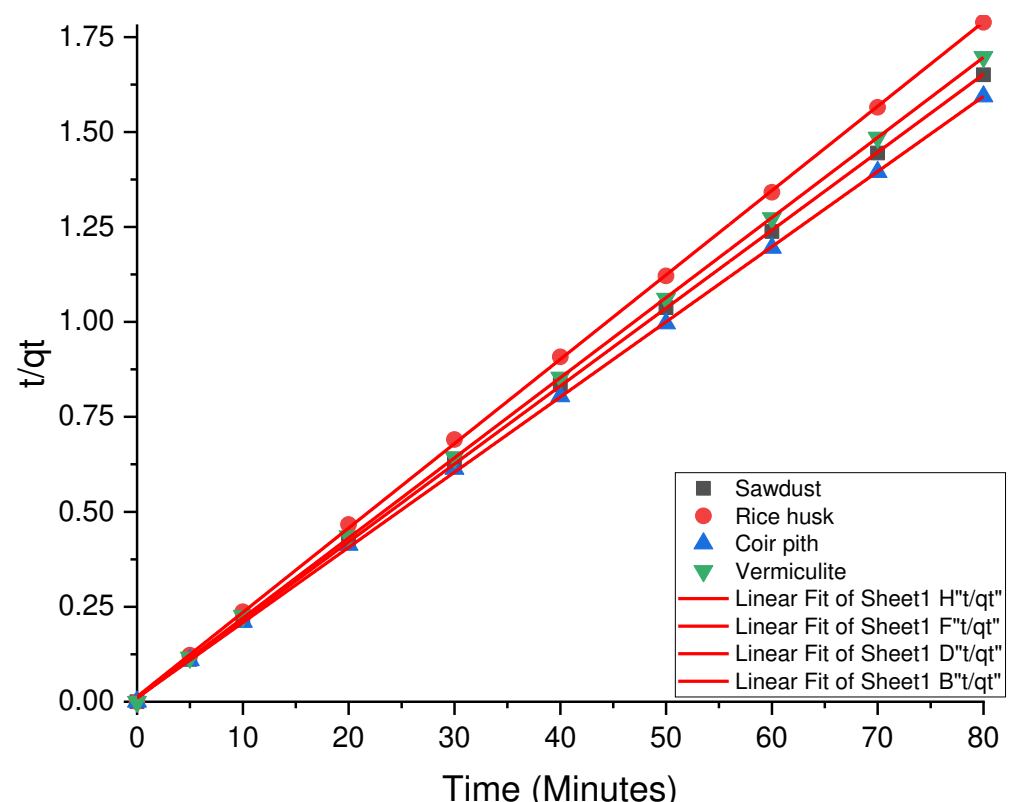

Figure 13: Pseudo-second-order kinetic plots for the bio-sorption of $\mathrm{Cr}$ (VI) onto different adsorbents

Table 4: Kinetic parameters for the removal of $\mathrm{Cr}$ (VI) by different adsorbents

\begin{tabular}{|c|c|c|c|c|c|}
\hline \multicolumn{2}{|c}{} & Sawdust & Rice husk & Coir pith & Vermiculite \\
\hline Order of Reaction & $\mathrm{q}_{\mathrm{e}, \mathrm{exp}}(\mathrm{mg} / \mathrm{g})$ & 48.5 & 44.8 & 50.2 & 47.2 \\
\hline \multirow{2}{*}{$\begin{array}{c}\text { Pseudo-first order } \\
\text { kinetic Model }\end{array}$} & $\mathrm{q}_{\mathrm{e}, \mathrm{cal}}(\mathrm{mg} / \mathrm{g})$ & 3.32 & 3.51 & 3.41 & 2.82 \\
\cline { 2 - 6 } & $\mathrm{K}_{1}\left(\mathrm{~min}^{-1}\right)$ & -0.00065 & -0.00066 & -0.0007 & -0.0007 \\
\cline { 2 - 6 } & $\mathrm{R}^{2}$ & 0.8424 & 0.8324 & 0.7998 & -0.8338 \\
\hline \multirow{3}{*}{$\begin{array}{c}\text { Pseudo-second order } \\
\text { kinetic Model }\end{array}$} & $\mathrm{q}_{\mathrm{e}, \mathrm{cal}}(\mathrm{mg} / \mathrm{g})$ & 48.7 & 45.0 & 50.5 & 47.4 \\
\cline { 2 - 6 } & $\mathrm{K}_{2}\left(\mathrm{~g} \mathrm{mg}^{-1} \mathrm{~min}^{-1}\right)$ & 0.04048 & 0.03703 & 0.03733 & 0.04643 \\
\cline { 2 - 6 } & $\mathrm{R}^{2}$ & 0.99992 & 0.99985 & 0.999989 & 0.99994 \\
\hline
\end{tabular}




\section{Conclusion}

This work utilizes ICP-MS for the detection and measurement of Chromium. Based upon the study of 5 different zones using QGIS, the maximum value of Chromium in groundwater was found to be $1000 \mu \mathrm{g} / \mathrm{l}$. The depletion of Chromium from the source was found to be non-linear. DRASTIC model suggested that the possible reasons behind this could be the presence of industries (although closed many years ago) in the region, anthropogenic activities and the geological topographies. The levels of Chromium were found under permissible limit only after a distance of $6.48 \mathrm{~km}$ from the source as suggested by QGIS. Other parameters like TDS, hydraulic conductivity and others as mentioned in IS 10500:2012 were also found beyond the permissible limits in nearby areas of the source. This calls for an action to tackle the water quality parameters in a simple and affordable manner and find methods to create a circular process for the reuse and recycle of the heavy metals (Chromium etc.) which are adsorbed on various modified bio-materials. The development of the circular process is one of the future scope of this work.

The present scope of this work included the modification of adsorbents of $\mathrm{Cr}$ (VI) for the remediation of ground and surface water. The reformation of the adsorbents via activation with different chemicals had better efficacy in comparison to the naturally available raw adsorbents. It was found that the adsorption and contact time was proportional, only to become constant after an interval of 60 minutes. The decreasing order of the adsorption as shown by the adsorbents can be listed as coir pith, saw dust, vermiculite and rice husk. $\mathrm{pH}$ also played a vital role in the enhancement of the adsorption process. After optimization of the results, $\mathrm{pH} 3$ and an adsorbent dose $1.5 \mathrm{~g} / \mathrm{l}$ gave the best results of adsorption percentage. The decreasing order of adsorption percentage can be listed as saw dust, coir pith, rice husk and vermiculite.

Considering the adsorption isotherms and kinetic studies, the reactions between Chromium and the bioadsorbents were found to follow pseudo-second order kinetics and the reactions were exothermic as the $\mathrm{B}_{\mathrm{T}}$ value was found to be greater than 0 . The adsorption followed kinetic isotherm of pseudo-second order in which regression value varied from 0.994-0.999. The affinity of the different adsorbents for the Cr (VI) was also observed, which exhibited that the Vermiculite bed showed higher interaction with the metal ions where value of $\mathrm{R}^{2}$ (correlation coefficient) was found to be 0.937 . For adsorption isotherm, Freundlich and Langmuir models were applied, Langmuir linear isotherm was established to be more accurate. The adsorption percentage $\mathrm{q}_{\max }\left(\mathrm{mgg}^{-1}\right)$ of Sawdust was found to be maximum and that of Vermiculite was minimum.

This works holds a clear vision to develop and implement such low-cost, affordable and environmental friendly measures to deal the problems of Chromium toxicity in and around tannery industries. It also welcomes other people of the industry and academia for future contributions.

\section{Author Contributions}

The manuscript has been written through the contributions of all the authors. All authors have given approval to the final version of the manuscript.

\section{Acknowledgement}

This work was supported by the Madan Mohan Malaviya University of Technology, Gorakhpur and Uttar Pradesh Jal Nigam.

\section{Funding}

Nil. 


\section{Conflict of interest}

On behalf of all authors, the corresponding author states that there is no conflict of interest.

\section{References}

[1] Tripathi SM, Chaurasia S (2018) Bioremediation of Groundwater: An Overview. Int. J. Appl. Eng. Res. 13 (24): $16825-16832$.

[2] Saha R, Nandi R, Saha B (2011) Sources and toxicity of hexavalent Chromium. J. Coord Chem. 64 (10):1782 - 1806. https://doi.org/10.1080/00958972.2011.583646

[3] Hu J, Lin Y, Zhu G (2016) Review on migration and transformation mechanisms of Chromium in the subsurface and remediation techniques for Chromium-contaminated sites. Environ Eng., 34 (S1):10531056.

[4] Kotaś J, Stasicka Z (2006) Chromium occurrence in the environment and methods of its speciation. Environ. Pollut. 107 (3):263 - 283.

[5] BIS IS: 10500 Indian Standard: Drinking Water-Specification, first revision 2012 Bureau of Indian Standards New Delhi, India, 2012.

[6] Zhou J, Wang Y, Wang J, Qiao D, Long D, Ling L (2016) Effective removal of hexavalent Chromium from aqueous solutions by adsorption on mesoporous carbon microspheres. J. Colloid Interface Sci. 462 (8):200 - 207. https://doi.org/10.1016/j.jcis.2015.10.001

[7] Liang LP, Wang Q, Xi FF., Tan WS, Zhang YT, Cheng LB, Wu Q, Xue YY, Meng X (2020) Effective Removal of Cr (VI) from Aqueous Solution Using Modified Orange Peel Powder: Equilibrium and Kinetic Study. Nat. Environ. Pollut. Technol. $19 \quad$ (4):1391 - 1398. https://doi.org/10.46488/NEPT.2020.v19i04.005.

[8] Mukhopadhyay B, Sundquist J, White E (2007) Hydro-geochemical controls on removal of Cr(VI) from contaminated groundwater by anion exchange. J. Appl. Geochem., 22 (2):380 - 387. https://doi.org/10.1016/j.apgeochem.2006.09.009.

[9] Tripathi SM, Chaurasia S (2020) Detection of Chromium in surface and groundwater and its bioabsorption using bio-wastes and vermiculite. Int. J. Eng. Sci. Technol. 23 (5):1153 - 1161. https://doi.org/10.1016/j.jestch.2019.12.002.

[10] Singh Ajai Vir, District Ground-water brochore Unnao District, Uttar Pradesh (AAP: 2012-13) (201213) http://cgwb.gov.in/District Profile/UP/Unnao.pdf. Accessed 05 January 2021

[11] Aller L, Bennet T, Lehr JH, Petty RJ (1987) DRASTIC: A standardized system for evaluating groundwater pollution potential using hydro geologic settings. USEPA document no. EPA/600/2-85018.

[12] Gogu RC, Dassargues A (2000) Current trends and future challenges in groundwater vulnerability assessment using overlay and index methods. Environ. Geol. 39 (6):549 - 559.

[13] Thirumalaivasan D, Karmeagam M, Venugopal K (2013) AHP-DRASTIC: software for specific aquifer vulnerability assessment using DRASTIC model and GIS. Environ. Model. Softw. 18 (7):645656. https://doi.org/10.1016/S1364-8152(03)00051-3

[14] Singh J, Mishra NS, Banerjee S, Sharma YC (2011) Comparative studies of physical characteristics of raw and modified Sawdust for their use as adsorbents for removal of Acid Dye. Bioresources 6 (3):2732 $-2743$.

[15] Franco DSP, Tanabe EH, Daniel AB, dos Reis GS, Lima ÉC, Dotto GL (2017) Alternative treatments to improve the potential of rice husk as adsorbent for methylene blue. Water Sci. Technol. 75.2:296 305.

[16] Suksabye P, Thiravetyan P (2012) Cr(VI) adsorption from electroplating plating wastewater by chemically modified coir pith. J. Environ. Manage. 102 (15):1 - 8. 
[17] Tian W, Kong X, Jiang M, Lei X, Duan X (2016) Hierarchical layered double hydroxide epitaxially grown on vermiculite for $\mathrm{Cr}(\mathrm{VI})$ removal. Mater. Lett. 175:110 $\quad$ - 113. https://doi.org/10.1016/j.matlet.2016.03.141

[18] Park D, Lim SR, Yun YS, Park JM (2008) Development of a new Cr(VI)-biosorbent from agricultural biowaste. Bioresour. Technol., 99 (18):8810 - 8818. https://doi.org/10.1016/j.biortech.2008.04.042

[19] Vijayvargia P, Vijayvergia R (2014) A Review on Limonia acidissima: Multipotential Medicinal Plant. Int. J. Pharm. Sci. Rev. Res. 28 (1):191 - 195.

[20] Deng S, Ting YP (2005) Fungal biomass with grafted poly (acrylic acid) for enhancement of Cu (II) and Cd (II) biomass. Langmuir 21 (13):5940-5948. https://doi.org/10.1021/la047349a.

[21] Chen S, Yue Q, Gao B, Xu X (2010) Equilibrium and kinetic adsorption study of the adsorptive removal of Cr (VI) using modified wheat residue. J. Colloid Interface Sci. 349 (1):256 - 264.

[22] Sumathi KMS, Mahimairaja S, Naidu R (2005) Use of low-cost biological wastes and vermiculite for removal of Chromium from tannery effluent. Bioresour. Technol. 96(3):309 - 316. https://doi.org/10.1016/j.biortech.2004.04.015

[23] Baral SS, Das SN, Rath P (2006) Hexavalent Chromium removal from aqueous solution by adsorption on treated sawdust. Biochem. Eng. J. 31:216-222.

[24] Gaballah I, Kilbertus G (1998) Recovery of heavy metal ions through decontamination of synthetic solutions and industrial effluents using modified barks. J. Geochem. Explor. 62 (1-3):241 - 286.

[25] Argun ME, Dursun S, Ozdemir C, Karatas M (2006) Heavy metal adsorption by modified oak sawdust: Thermodynamics and kinetics. J. Hazard. Mater. 141:77 - 85 . https://doi.org/10.1016/j.jhazmat.2006.06.095

[26] Garg VK, Gupta R, Kumar R, Gupta RK (2004) Adsorption of Chromium from aqueous solution on treated sawdust. Bioresour. Technol. 92:79 - 81. https://doi.org/10.1016/j.biortech.2003.07.004

[27] Langmuir I (1918) The Adsorption of Gases on Plane Surfaces of Glass, Mica and Platinum, J. Am. Chem. Soc. 40 (9):1361 - 1403. https://doi.org/10.1021/ja02242a004.

[28] Freundlich H (1906) Adsorption in Solution. Zeitschrift für Physikalische Chemie. 57:384 - 470.

[29] Piccin JS, Dotto GL, Pinto LAA (2011) Adsorption isotherms and Thermochemical Data of F D \& C Red N 40 Binding by Chitosan. Braz. J. Chem. Eng. 28 (02):295 - 304. https://doi.org/10.1590/S010466322011000200014

[30] Sierra-Trejo PV, Guibal E, Louvier-Hernández JF (2020) Arsenic sorption on chitosan-based sorbents: comparison of the effect of molybdate and tungstate loading on As (V) sorption properties. J Polym Environ. 28 (3):934 - 947. https://doi.org/10.1007/s10924-020-01654-6.

[31] Ayub A, Raza ZA, Majeed MI, Tariq MR, Irfan A (2020) Development of sustainable magnetic chitosan biosorbent beads for kinetic remediation of arsenic contaminated water. Int. J. Biol. Macromol. 163 (15):603 - 617. https://doi.org/10.1016/j.ijbiomac.2020.06.287.

[32] Manivannan P, Arivoli S, Mohammed SR (2015) Adsorption Studies on Chromium (VI) removal from Aqueous Solution using Activated Hibiscus sabdariffa Stem Nano Carbon. Int. J. ChemTech Res. 8 (12):662- 673 . 